\title{
Bio-Psycho-Social Factors Affecting Women's Sexual Function during Pregnancy: A Narrative Review
}

\author{
Nastaran Bagherian Afrakoti ${ }^{1,2} \&$ Zohreh Shahhosseini ${ }^{1,3}$ \\ ${ }^{1}$ Department of Reproductive Health and Midwifery, Nursing and Midwifery Faculty, Mazandaran University of \\ Medical Sciences, Sari, Iran \\ ${ }^{2}$ Student Research Committee, Mazandaran University of Medical Sciences, Sari, Iran \\ ${ }^{3}$ Traditional and Complementary Medicine Research Center, Mazandaran University of Medical Sciences, Sari, \\ Iran
}

Correspondence: Zohreh Shahhosseini, Nursing and Midwifery Faculty, Mazandaran University of Medical Sciences, Sari, Iran; Vesal Street, Amir Mazandarani Boulevard, Sari, Po Box: 4816715793, Mazandaran Province, Iran. Tel: 98-111-3336-7345. Fax: 98-111-3336-7342. E-mail: zshahhosseini@yahoo.com

Received: November 29, 2015 Accepted: January 12, 2016 Online Published: February 24, 2016

doi:10.5539/gjhs.v8n10p9

URL: http://dx.doi.org/10.5539/gjhs.v8n10p9

\begin{abstract}
Background: Sexual function is a multidimensional phenomenon which is affected by many biological, psychological and social factors. Since sexual problems can have many effects on other aspects of the personal and social lives, and on the other hand sexual function can go through changes during pregnancy, this study has been designed in order to review the factors affecting women's sexual function during pregnancy.

Methods: A comprehensive search using key words: pregnancy, childbirth, sexual function and sexual disorder were conducted in the web search engines Google and Google Scholar, as well as the databases of PubMed, ProQuest, and Cochrane library. Science Direct, Scientific Information Database and Magiran. A total of 29 relevant international and Iranian literature sources meeting the inclusion criteria were included.

Results: The results led to organizing the findings related to sexual function during pregnancy in three categories, namely biological factors, psychological factors and social factors.

Conclusion: It is suggested that evaluation of sexual health during pregnancy must become a main pivot of routine prenatal care. In this way, it is necessary health care providers to be aware of a number of risk factors that may contribute to sexual dysfunction in pregnant women.
\end{abstract}

Keywords: pregnancy, childbirth, sexual function, sexual disorder

\section{Introduction}

Sexual function is a multidimensional phenomenon which is affected by many biological, psychological and social factors (Shahhosseini, Gardeshi, Pourasghar, \& Salehi, 2014; Yeniel \& Petri, 2014). According to the definition by World Health Organization, sexual health is a physical, psychological and social concept with a positive approach toward sexual relationship, which cannot be solely defined as the lack of sexual performance disorder (World Health Organsation, 2015). Putting importance on sexuality is realistic, because sexual problem can have various effects on other aspects of personal and social life; in a way that it is the cause of some mental disturbances, low self-esteem, mental conflicts and failures and it finally affects qualify of life (Bayrami, 2008; Leite et al., 2009; Lowenstein, Mustafa, \& Burke, 2013; Safarinejad, 2006).

Women's sexual function is a form of ability to reach excitement or sexual desire, lubrication or arousal and orgasm, which leads to a level of health along with good quality of life (Basson, 2005; Leite et al., 2009). In contrast, female sexual dysfunction by disturbing sexual desire, arousal and orgasm and also pain during intercourse, causes distress in the person and also interpersonal problems (Ibrahim, Ahmed, \& Ahmed, 2013). In a study, the prevalence of female sexual dysfunction was reported to be 43.1 percent. However, this prevalence is heavily affected by the culture in that area (Safarinejad, 2006; Shifren, Monz, Russo, Segreti, \& Johannes, 2008).

Pregnancy is a period with numerous physical, psychological and social changes which may affect sexual function. Sexual desire and sexual function of pregnant women and their spouses are unpredictable, so they may 
increase, decrease or have no changes (Bayrami, 2008; Gałąka, Drosdzol-Cop, Naworska, Czajkowska, \& Skrzypulec-Plinta, 2015). For example, desire for intercourse decrease during pregnancy (more than 50 percent), especially in the third trimester (Aslan, Aslan, Kızılyar, Ispahi, \& Esen, 2005; Leite et al., 2009; Pauleta, Pereira, \& Graça, 2010). In a prospective cohort study on 40 pregnant women, significant relationship was also observed between decrease in sexual function and pregnancy (Aslan et al., 2005). In another cross-sectional study on 589 pregnant women, the result showed decrease in sexual function during pregnancy especially in the third trimester, and also, decrease in clitoris sensitively, reduction of sexual desire and orgasm disorders were mentioned as the most prevalent sexual disorders during pregnancy (Erol et al., 2007). Nonetheless, the issues related to couple's sexual function and sexual life in this period have gained little attention and discussion from health care providers (Güleroğlu \& Beşer, 2014).

According to the fact that sexual function is an important part of marital life and undergoes a lot of changes during pregnancy, the purpose of this review study is to investigate the factors affecting sexual function during pregnancy.

\section{Method}

In order to present this review article, researchers used Google Scholar general search engine, and then more specific: Science Direct, ProQuest, PubMed and Cochrane library, Scientific Information Database (SID), Magiran. From 269 related documents has been extracted from 1970 to 2015 by using the keywords: pregnancy, childbirth, sexual function and sexual disorder, 29 articles meeting the inclusion criteria were included. In this processes the five steps were followed: 1. Identifying the research question; 2. Search methods for Identifying relevant studies; 3. Study selection; 4. Charting the data, collating, summarizing and 5. Reporting the results (Cowley et al., 2015) (Figure 1)

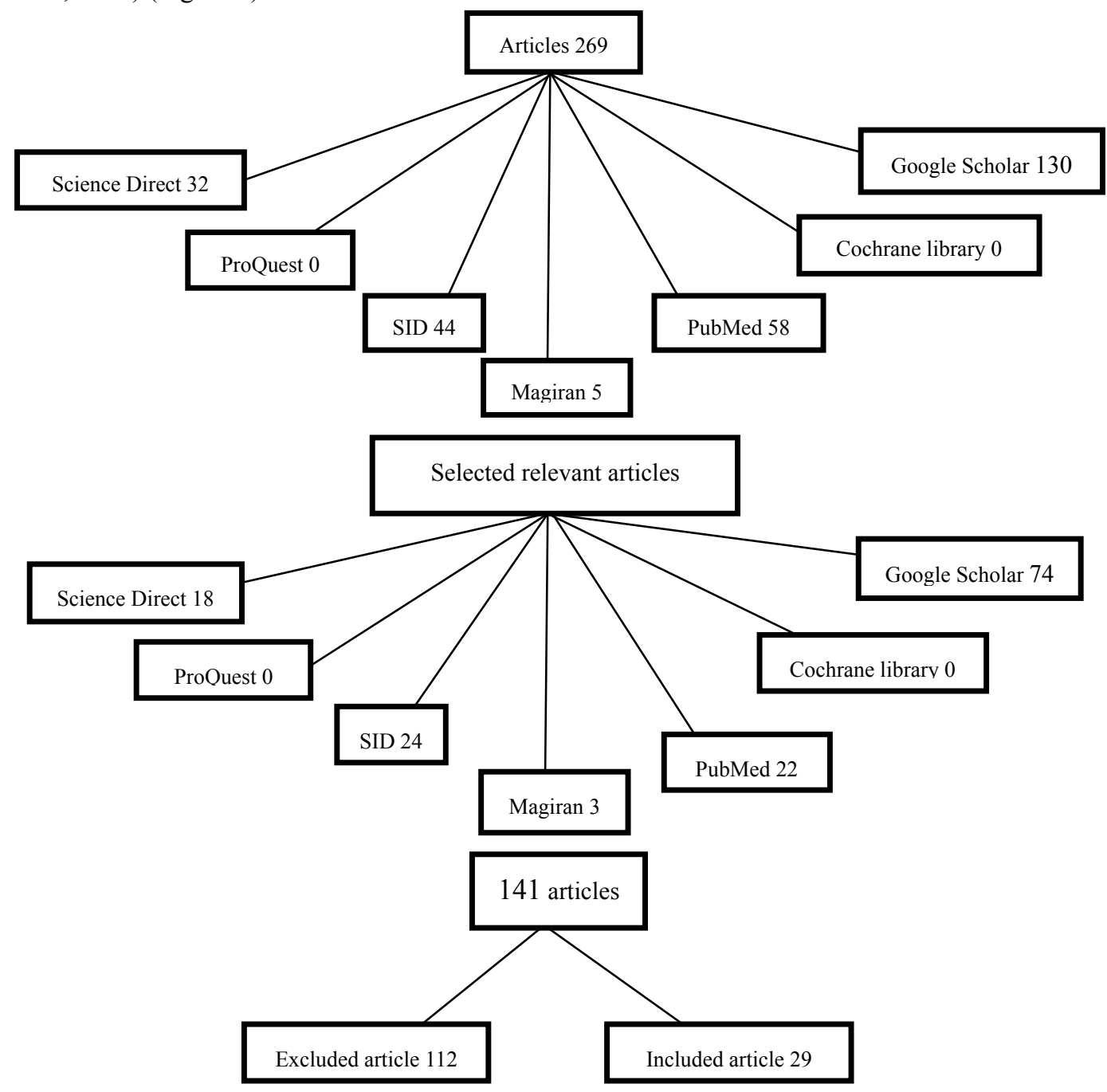

Figure 1. Search methods for identifying relevant studies 


\section{Results}

The results of reviewing the articles led to organizing the findings related to sexual function during pregnancy in three categories, namely biological factors, psychological factors and social factors. (Table 1)

Category one comprises factors such as Hormonal changes, nausea, fatigue, weight gain, big belly, big breasts and breast pain, painful intercourse, anatomical changes in the urinary tract and pelvic floor, pregnancy age and number of pregnancies and deliveries. Category two comprises factors such as Feeling difficulty in intercourse positions, poor body image, decreased sexual attraction, fear of bleeding, miscarriage and infection, fetal injury and premature birth, premature rupture of membranes, the stress of motherhood, unwanted pregnancy, marital satisfaction and Category three comprises factors such as Age, education, employment, the duration of marriage, number of deliveries, satisfaction with family income, religious factors such as belief in damage to the fetus, abortion, the start of preterm labor , the hymen rupture of the female fetus and the fetal blindness and marital satisfaction.

Table 1. Different categories and sub categories of affecting factors on women's sexual function during pregnancy

Hormonal changes (Koshaka, 1998; Kitzinger, 1983); Nausea and fatigue (Kitzinger, 1983); Weight gain and big belly (Erol, 2007); Big breasts and breast pain (Kitzinger,

Biological factors 1983); Painful intercourse (Glowacka, 2014); Anatomical changes in the urinary tract and pelvic floor (Change, 2014); Pregnancy age and number of pregnancies and deliveries (Eryilmaz, 2004; Tosun, 2014).

Feeling difficulty in intercourse positions and poor body image (Sydow, 1999); decreased

Psychological factors sexual attraction (Bayrami, 2008); Fear of bleeding and miscarriage (Judicibus, 2002; Shoja, 2012); Fear of fetal injury and premature birth and premature rupture of membranes (Fok, 2005); The stress of motherhood (Sydow, 1999); Unwanted pregnancy (Barimany, 2008); Marital satisfaction (Sydow, 2008).

Age, education, employment (Eryilmaz, 2004); Duration of marriage and number of deliveries (Eryilmaz, 2004); Satisfaction with family income (Bayrami, 2008); Religious factors such as belief in damage to the fetus, abortion, the start of preterm labor, the hymen rupture of the female fetus and the fetal blindness (Naim,2000; Shoja, 2012); Marital satisfaction (Malarewicz, 2006).

\section{Discussion}

Pregnancy comes with many physical and psychological changes which affects sexual function and relationships with sexual partner.

The bio-psycho-social factors related to sexual function during pregnancy in the three groups are:

\subsection{Biological Factors Related to Sexual Function during Pregnancy}

Among biological factors which affect sexual relationship during pregnancy, hormonal changes such as an increase in estrogen, progesterone and prolactin, lead to biological changes like nausea, fatigue and breast pain and affect sexual desire and arousal in women (Kitzinger, 1983; Zakšek, 2015). Moreover, an increase in the relaxin hormone in pregnancy leads to increases in the size of vaginal epithelial cells and eventually results in reduced vaginal sensitively (Kohsaka et al., 1998). Recent studies show that this period of hormone changes causes decreased clitoris sensitively, orgasm disorder and decreased libido even up to six months after delivery

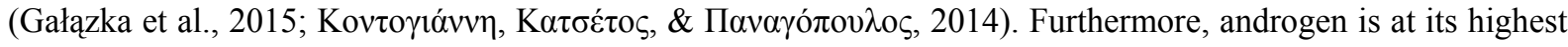
level at the beginning of pregnancy and then the level decreases in the third trimester, which can be a reason why sexual desire decreases a lot in the third trimester (Warnock, Clayton, Croft, Segraves, \& Biggs, 2006). On the other hand, in a cross-sectional study on 589 pregnant women, no relationship was found between decreased sexual function in the third trimester and mother's serum androgen levels (Erol et al., 2007).

Morning sickness and pelvic vascular congestion are common problems in the first and second trimesters and are a reason for decreased sexual desire (Serati et al., 2010). Although gaining weight is a normal pregnancy process, women's concern about increased body fat and physical form change causes worries and decreased sexual desire. Moreover, abdomen enlargement brings inconvenience at the time of intercourse (Erol et al., 2007). Among other 
biological changes, breast pain in the first trimester due to its enlargement can be mentioned, which can affect

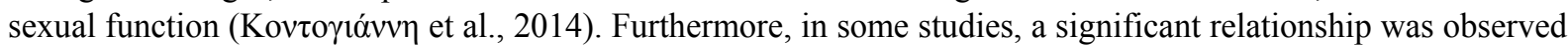
between pregnancy age and number of pregnancies and deliveries and sexual function (Eryilmaz, Ege, \& Zincir, 2004; Güleroğlu \& Beşer, 2014).

Dyspareunia and vaginismus are quite common during pregnancy and researches show that the anxiety of pain during pregnancy makes it continue and worsen even up to three months after delivery (Glowacka, Rosen, Chorney, \& George, 2014). Also it is showed that pregnancy brings about anatomic changes in the urinary tract and pelvic floor, which may cause urinary incontinence which itself can affect sexual function (Chang et al., 2014).

\subsection{Psychological Factors Related to Sexual Function during Pregnancy}

Sexual changes and problems in pregnancy can be due to the women's emotional response against changes during pregnancy (De Judicibus \& McCabe, 2002). Fatigue, tiredness and discomfort in intercourse positions due to abdomen enlargement and mother's undesirable body-image of her growing abdomen and decreased sexual attraction may affect the sexual relationship (Bayrami, 2008; von Sydow, 1999). Furthermore, many emotional, psychological and stressing factors in pregnancy such as fear of bleeding, abortion and infection, injury to the fetus, premature rupture of membranes, premature delivery and anxiety about if she will be able to be a mother and take care of a baby affect sexual desire (Bartellas, Crane, Daley, Bennett, \& Hutchens, 2000; De Judicibus \& McCabe, 2002; Eryilmaz et al., 2004; Jones, Chan, \& Farine, 2011; von Sydow, 1999). In a study conducted on Chinese and Taiwanese women, one of the reasons of decreased sexual function was fear of hurting the fetus (Fok, Chan, \& Yuen, 2005).

In this way, a study explains unplanned pregnancy and its negative psychological effects as a reason for sexual function disorder during pregnancy (Bayrami, 2008). Finally, it has been shown in a research that sexual pleasure during pregnancy is influenced by the relationship with the sexual partner (von Sydow, 2008).

\subsection{Social Factors Related to Sexual Function during Pregnancy}

Social and cultural factors can influence a couple's sexual life. Demographic factors such as education, employment status, marriage duration and ethnic groups influence sexual function during pregnancy. In a research, it was shown that some factors such as old age, low education and marriage duration of more than ten years, negatively influenced sexual function during pregnancy (Güleroğlu \& Beşer, 2014). In another study, a significant relationship was found between sexual function and education, marriage duration and number of deliveries, but no relationship was found between sexual function and the age and employment status of pregnant women (Eryilmaz et al., 2004). A significant relationship has been found between dissatisfaction with family income and sexual function disorder (Bayrami, 2008).

Moreover, cultural factors, beliefs and norms influence sexual function during pregnancy. A research on Pakistani pregnant women has shown that they have decreased sexual function due to beliefs such as hurting the fetus, abortion and premature delivery (Naim \& Bhutto, 2000). Furthermore, in a study on Iranian women, the reason for refraining from sexual activity believed in female fetus's losing her virginity and getting blind (Shoja, 2012). In a research it was shown that the couple believed having sexual relationship during pregnancy is a cause of increased self-confidence and improved marital relationship (von Sydow, 1999). In this way, in a meta-analysis of 59 studies it was shown that if the couple had intercourse during pregnancy and enjoyed it, there should be a better marital relationship during pregnancy and after delivery (Malarewicz, Szymkiewicz, \& Rogala, 2006).

In conclusion by considering the results of the conducted studies that indicate sexual function changes during pregnancy and returning to the state of sexual health will take long after the end of pregnancy and will affect the couple's relationship, attention should be paid to the different aspects of women's sexual health during pregnancy. In this way, health care system should be consider systematic and organized programs to investigate this issue. Finally the need for educating health care providers to be aware of a number of risk factors that may contribute to sexual dysfunction in pregnant women and how to manage sexual health during pregnancy must become a main pivot of pregnancy care.

\section{Acknowledgments and Funding}

We would like to express our appreciation to Mazandaran University of Medical Sciences for funding this research (Grant No. 94-287).

This project was funded and supported by Student Research Committee, Mazandaran University of Medical Sciences, Grant No. 94-287. 


\section{Conflict of Interest}

The authors declare that there is no conflict of interests regarding the publication of this paper.

\section{References}

Aslan, G., Aslan, D., Kızılyar, A., Ispahi, C., \& Esen, A. (2005). A prospective analysis of sexual functions during pregnancy. International Journal of Impotence Research, 17(2), 154-157. http://dx.doi.org/10.1038/ sj.ijir.3901288

Bartellas, E., Crane, J. M., Daley, M., Bennett, K. A., \& Hutchens, D. (2000). Sexuality and sexual activity in pregnancy. BJOG: An International Journal of Obstetrics \& Gynaecology, 107(8), 964-968. http://dx.doi. org/10.1111/j.1471-0528.2000.tb10397.x

Basson, R. (2005). Women's sexual dysfunction: Revised and expanded definitions. Canadian Medical Association Journal, 172(10), 1327-1333. http://dx.doi.org/10.1503/cmaj.1020174

Bayrami, R. S., Koochaksariie, N., Pezeshki, F. R., \& Zakaria, M. (2008). Sexual dysfunction in couples and its related factors during pregnancy. Journal of Reproduction \& Infertility, 9(3), 271-282.

Chang, S.-R., Chen, K.-H., Lin, H.-H., Lin, M.-I., Chang, T.-C., \& Lin, W.-A. (2014). Association of mode of delivery with urinary incontinence and changes in urinary incontinence over the first year postpartum. Obstetrics \& Gynecology, 123(3), 568-577. http://dx.doi.org/10.1097/AOG.0000000000000141

Cowley, S., Whittaker, K., Malone, M., Donetto, S., Grigulis, A., \& Maben, J. (2015). Why health visiting? Examining the potential public health benefits from health visiting practice within a universal service: A narrative review of the literature. Int ernational Journal of Nursing Studies, 52(1), 465-480. http://dx.doi. org/10.1016/j.ijnurstu.2014.07.013

De Judicibus, M. A., \& McCabe, M. P. (2002). Psychological factors and the sexuality of pregnant and postpartum women. Journal of Sex Research, 39(2), 94-103. http://dx.doi.org/10.1080/00224490209552128

Erol, B., Sanli, O., Korkmaz, D., Seyhan, A., Akman, T., \& Kadioglu, A. (2007). A Cross-Sectional Study of Female Sexual Function and Dysfunction During Pregnancy. The Journal of Sexual Medicine, 4(5), 1381-1387. http://dx.doi.org/10.1111/j.1743-6109.2007.00559.x

Eryilmaz, G., Ege, E., \& Zincir, H. (2004). Factors affecting sexual life during pregnancy in eastern Turkey. Gynecologic \& Obstetric Investigation, 57(2), 103-108. http://dx.doi.org/10.1159/000075582

Fok, W. Y., Chan, L. Y. S., \& Yuen, P. M. (2005). Sexual behavior and activity in Chinese pregnant women. Acta Obstetricia et Gynecologica Scandinavica, 84(10), 934-938. http://dx.doi.org/10.1111/j.0001-6349. 2005.00743.x

Gałązka, I., Drosdzol-Cop, A., Naworska, B., Czajkowska, M., \& Skrzypulec-Plinta, V. (2015). Changes in the sexual function during pregnancy. The Journal of Sexual Medicine, 12(2), 445-454. http://dx.doi.org/10. $1111 /$ jsm. 12747

Glowacka, M., Rosen, N., Chorney, J., \& George, R. B. (2014). Prevalence and Predictors of Genito-Pelvic Pain in Pregnancy and Postpartum: The Prospective Impact of Fear Avoidance. The Journal of Sexual Medicine, 11(12), 3021-3034. http://dx.doi.org/10.1111/jsm.12675

Güleroğlu, F. T., \& Beşer, N. G. (2014). Evaluation of sexual functions of the pregnant women. The Journal of Sexual Medicine, 11(1), 146-153. http://dx.doi.org/10.1111/jsm.12347

Ibrahim, Z. M., Ahmed, M. R., \& Ahmed, W. A. S. (2013). Prevalence and risk factors for female sexual dysfunction among Egyptian women. Archives of Gynecology \& Obstetrics, 287(6), 1173-1180. http://dx.doi.org/10.1007/s00404-012-2677-8

Jones, C., Chan, C., \& Farine, D. (2011). Sex in pregnancy. Canadian Medical Association Journal, 183(7), 815-818. http://dx.doi.org/10.1503/cmaj.091580

Kitzinger, S. (1983). Womans'experience of sex (D. Kindesley Ed., Vol. 6). London: Penguin.

Kohsaka, T., Min, G., Lukas, G., Trupin, S., Campbell, E. T., \& Sherwood, O. D. (1998). Identification of specific relaxin-binding cells in the human female. Biology of Reproduction, 59(4), 991-999. http://dx.doi. org/10.1095/biolreprod59.4.991

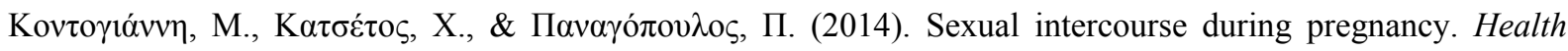
Science Journal, 6(1), 83-87. 
Leite, A. P. L., Campos, A. A. S., Dias, A. R. C., Amed, A. M., De Souza, E., \& Camano, L. (2009). Prevalence of sexual dysfunction during pregnancy. Revista da Associação Médica Brasileira, 55(5), 563-568. http://dx.doi.org/10.1590/S0104-42302009000500020

Lowenstein, L., Mustafa, S., \& Burke, Y. (2013). Pregnancy and normal sexual function. Are they compatible? The Journal of Sexual Medicine, 10(3), 621-622. http://dx.doi.org/10.1111/jsm.12098

Malarewicz, A., Szymkiewicz, J., \& Rogala, J. (2006). Sexuality of pregnant women. Ginekologia polska, 77(9), 733-739.

Naim, M., \& Bhutto, E. (2000). Sexuality during pregnancy in Pakistani women. Journal Pakistan Medical Association, 50(1), 38-43.

Pauleta, J. R., Pereira, N. M., \& Graça, L. M. (2010). Sexuality during pregnancy. The Journal of Sexual Medicine, 7(1), 136-142. http://dx.doi.org/10.1111/j.1743-6109.2009.01538.x

Safarinejad, M. (2006). Female sexual dysfunction in a population-based study in Iran: Prevalence and associated risk factors. International Journal of Impotence Research, 18(4), 382-395. http://dx.doi.org/10. 1038/sj.ijir.3901440

Serati, M., Salvatore, S., Siesto, G., Cattoni, E., Zanirato, M., Khullar, V., ... Bolis, P. (2010). Female sexual function during pregnancy and after childbirth. The Journal of Sexual Medicine, 7(8), 2782-2790. http://dx.doi.org/10.1111/j.1743-6109.2010.01893.x

Shahhosseini, Z., Gardeshi, Z. H., Pourasghar, M., \& Salehi, F. (2014). A review of affecting factors on sexual satisfaction in women. Materia socio-medica, 26(6), 378-381. http://dx.doi.org/10.5455/msm.2014.26.378381

Shifren, J. L., Monz, B. U., Russo, P. A., Segreti, A., \& Johannes, C. B. (2008). Sexual problems and distress in United States women: Prevalence and correlates. Obstetrics \& Gynecology, 112(5), 970-978. http://dx.doi.org/10.1097/AOG.0b013e3181898cdb

Shoja, M. (2012). Changes in Sexual and Behavioral Relationships among Couples during Pregnancy. Qom University of Medical Sciences Journal, 5(3). 23-35.

von Sydow, K. (1999). Sexuality during pregnancy and after childbirth: A metacontent analysis of 59 studies. Journal of Psychosomatic Research, 47(1), 27-49. http://dx.doi.org/10.1016/S0022-3999(98)00106-8

von Sydow, K. (2008). 53 Sexuality in pregnancy and the postpartum period. The Fetus \& Mother, 430.

Warnock, J. K., Clayton, A., Croft, H., Segraves, R., \& Biggs, F. C. (2006). Comparison of androgens in women with hypoactive sexual desire disorder: Those on combined oral contraceptives (COCs) vs. those not on COCs. The Journal of Sexual Medicine, 3(5), 878-882. http://dx.doi.org/10.1111/j.1743-6109.2006.00294.x

World health organsation. (2015). Sexual health. Retrieved November, 2015, from http://www.who.int/topics/ sexual_health/en

Yeniel, A., \& Petri, E. (2014). Pregnancy, childbirth, and sexual function: Perceptions and facts. International urogynecology journal, 25(1), 5-14. http://dx.doi.org/10.1007/s00192-013-2118-7

Zakšek, T. Š. (2015). Sexual Activity during Pregnancy in Childbirth and after Childbirth. Sexology in Midwifery.

\section{Copyrights}

Copyright for this article is retained by the author(s), with first publication rights granted to the journal.

This is an open-access article distributed under the terms and conditions of the Creative Commons Attribution license (http://creativecommons.org/licenses/by/3.0/). 